Research Paper

\title{
Effects of AQP5 gene silencing on proliferation, migration and apoptosis of human glioma cells through regulating EGFR/ERK/ p38 MAPK signaling pathway
}

\author{
Jian Yang ${ }^{1, *}$, Jian-Nan Zhang ${ }^{2, *}$, Wei-Lin Chen ${ }^{1}$, Gui-Song Wang ${ }^{1}$, Qing Mao ${ }^{1}$, Shan-Quan Li², \\ Wen-Hao Xiong ${ }^{1}$, Ying-Ying Lin ${ }^{1}$, Jian-Wei Ge ${ }^{1}$, Xiao-Xiong Li $^{1}$, Zhao Gu${ }^{1}$, Chun-Run Zhao ${ }^{1}$ \\ ${ }^{1}$ Department of Neurosurgery, Renji Hospital, School of Medicine, Shanghai Jiaotong University, Shanghai 200127, P. R. China \\ ${ }^{2}$ Operation Room, Shanghai Children's Medical Center, School of Medicine, Shanghai Jiaotong University, Shanghai 200127, \\ P. R. China \\ *These authors contributed equally to this work
}

Correspondence to: Jian-Wei Ge, email: gejianweior@163.com

Xiao-Xiong Li, email: lixiaoxiongzj@yeah.net

Keywords: AQP5, U87-MG cells, U251 cells, LN229 cells, cell apoptosis

Received: May 17, $2016 \quad$ Accepted: January 06, $2017 \quad$ Published: March 22, 2017

Copyright: Jian Yang et al. This is an open-access article distributed under the terms of the Creative Commons Attribution License 3.0 (CC BY 3.0), which permits unrestricted use, distribution, and reproduction in any medium, provided the original author and source are credited.

\section{ABSTRACT}

We investigated the effects of aquaporin 5 (AQP5) gene silencing on the proliferation, migration and apoptosis of human glioma cells through regulating the EGFR/ERK/p38MAPK signaling pathway. qRT-PCR was applied to examine the mRNA expressions of AQP5 in five human glioma cell lines. U87-MG, U251 and LN229 cells were selected and assigned into blank, vector, AQP5 siRNA and FlagAQP5 groups. MTT assay was used to measure cell proliferation. Flow cytometry (FCM) with AnnexinVFITC/PI double staining and PI staining were employed to analyze cell apoptosis and cell cycle respectively. Scratch test was used to detect cell migration. Western blotting was performed to determine the EGFR/ERK/p38 MAPK signaling pathway-related proteins. Results showed that the positive expression of AQP5 in primary glioblastoma was associated with the tumor size and whether complete excision was performed. The mRNA expressions of AQP5 in cell lines of U87-MG, U251 and LN229 were significantly higher than in U373 and T98G. The proliferation rates of U87-MG, U251 and LN229 cells in the AQP5 siRNA group were lower than in the vector and blank groups. The apoptosis rate increased in the AQP5 siRNA group compared with the vector group. Scratch test demonstrated that $A Q P 5$ gene silencing could suppress cell migration. Compared with the vector and blank groups, the AQP5 siRNA group showed decreased expressions of the ERK1/2, p38 MAPK, p-ERK1/2 and p-p38 MAPK proteins. AQP5 gene silencing could inhibit the cell proliferation, reduce cell migration and promote the cell apoptosis of U87-MG, U251 and LN229 by suppressing EGFR/ERK/p38 MAPK signaling pathway.

\section{INTRODUCTION}

Glioma, the most common malignant tumor of the central nervous system, is characterized by high morbidity, recurrence rate and mortality, and low cure rate [1]. World Health Organization guidelines classify glioma into grades I IV according to the pattern of the tumor; the tumors in grades I-II are referred to low-grade gliomas (LGG) and those in grades III-IV are cited as high-grade gliomas (HGG) [2]. HGG, featured by high aggressiveness and poor prognosis, are by now the most common primary brain tumors occurred in adults [3, 4]. Patients with LGG have a relatively higher average survival time compared with those with HGG [5]. Surgery is still recognized as the first line therapy for glioma, though the tendency of glioma cells to infiltrate normal brain tissue makes it unachievable to conduct total resection, and glioma recurs in $90 \%$ of patients in the resection margin $[6,7]$. Traditional treatment strategies typically combine tumor resection with radiotherapy and chemotherapy, but therapeutic effects are often unsatisfactory [8, 9]. Improvement in the outcome may depend on a better 
understanding of the scientific basis of glioma-genesis and the clinical application of such knowledge. Molecular mechanisms of the invasiveness and progression of glioma have been widely explored, but effective therapeutic target has not yet been found $[10,11]$.

Aquaporins (AQPs) are water channel proteins that have been recognized exist in virtually all living organisms, allowing water to move rapidly through the plasma membrane in almost cells [12]. Water-selective AQPs are involved in multiple biological functions, including neuro-excitation, cell migration, brain edema and trans-epithelial fluid transport. Modulators of AQP function suggest its clinical significance in neurology, oncology, nephrology and dermatological indications [13]. Aquaporin5 (AQP5), one of subtypes of aquaporin family, is involved in regulation of mucin expression and secretion as well as fluid secretion of airway submucosal gland [14]. High AQP5 expression in colon, breast and pancreatic cancer cells affects the invasion, proliferation and metastasis of the tumor cells $[15,16,17]$. In addition, AQP5 gene silencing inhibits the proliferation of endometrial glandular epithelial cells notably [18], suggesting that altered $A Q P 5$ expression plays a crucial role in tumor progression. Up-regulation of Aquaporin 1 (AQP1) gene has been reported to promote the invasiveness of glioma cells [19, 20]. However, the role of AQP5 gene expression in glioma has not been studied. In addition, epidermal growth factor receptor (EGFR) and mitogenactivated protein kinase (MAPK) have been reported to promote tumor proliferation, migration and invasion [21-23]. In this study, we investigated how $A Q P 5$ gene silencing might influence the proliferation and apoptosis of human glioma cells and the involvement of the EGFR/extracellular signalregulated kinase (ERK)/MAPK pathway to provide a new direction for the treatment of glioma.

\section{RESULTS}

\section{Comparisons of the AQP5 expression between primary glioblastoma and normal brain tissues}

As shown in Figure 1. Compared with the normal brain tissue, the expressions of AQP5 significantly increased in primary glioblastoma, and distributed both in cytoplasm and nuclei. These indicated that AQP5 over expressed in primary glioblastoma.

\section{Association between the AQP5 expression and clinicopathological characteristics of patients with primary glioblastoma}

As shown in Table 1, the positive expression of AQP5 in primary glioblastoma was associated with the tumor size and whether complete excision was performed $(P<0.05)$. The larger diameter and partial excision were accompanied with higher positive expression of $A Q P 5$. There was no association between the positive expression of $A Q P 5$ and age, gender, KPS score and tumor location $(P>0.05)$.

\section{Screening of cell lines with $A Q P 5$ overexpression}

qRT-PCR was applied to examine the mRNA expressions of AQP5 in cell lines of U87-MG, U251, U373, T98G and LN229. As shown in Figure 2, the mRNA expressions of AQP5 in U87-MG, U251 and LN229 were significantly higher than in U373 and T98G. Therefore, U87-MG, U251 and LN229 were chosen in this study for further experiments.

\section{Transfection efficiency of AQP5 overexpression plasmid and the AQP5 siRNA plasmid}

U87-MG, U251 and LN229 were transfected with $A Q P 5$ siRNA and Flag $A Q P 5$, and transfection efficiency of overexpression plasmid and AQP5 siRNA plasmid were detected by Western Blotting (Figure 3). Compared with the vector group, in U87-MG, U251 and LN229 cells it could be found that $A Q P 5$ gene silencing reduced $A Q P 5$ protein levels by more than $75 \%$ and transfection efficiency of AQP5 siRNA reached more than $75 \%$ $(P<0.05)$. In the Flag $A Q P 5$ group, the expressions of AQP5 in U87-MG, U251 and LN229 cells at least doubled $(P<0.05)$.

\section{Effect of AQP5 gene silencing on the proliferation of U87-MG, U251 and LN229 cells}

MTT assay was used to determine the effect of AQP5 gene silencing and AQP5 overexpression on the proliferation of U87-MG, U251 and LN229 cells at time points of $24 \mathrm{~h}, 48 \mathrm{~h}, 72 \mathrm{~h}$ and $96 \mathrm{~h}$ after transfection

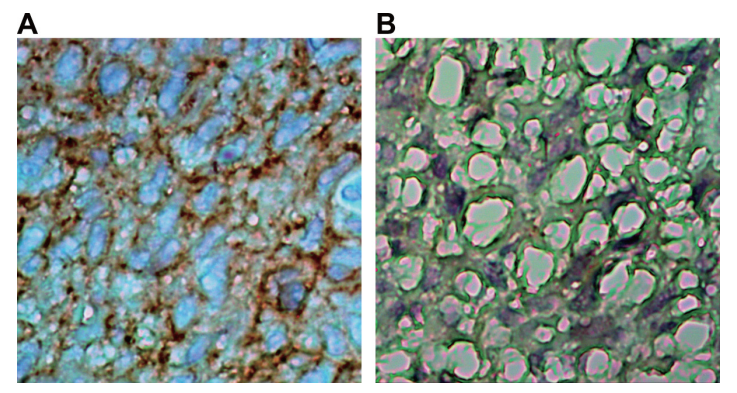

Figure 1: Comparisons of AQP5 expressions in primary glioblastoma and normal brain tissue detected by IHC $(\times 400)$. (A) primary glioblastoma tissue; (B) normal brain tissue. 
Table 1: Association between the AQP5 expression and clinicopathological characteristics of patients with primary glioblastoma

\begin{tabular}{|c|c|c|c|c|c|c|}
\hline \multicolumn{2}{|c|}{ Clinicopathological characteristic } & \multirow{2}{*}{$\frac{\text { Case }}{10}$} & \multirow{2}{*}{$\frac{\text { Positive expression (case) }}{8}$} & \multirow{2}{*}{$\frac{\text { Positive rate }(\mathbf{\%})}{80.0}$} & \multirow{2}{*}{$\frac{\chi^{2}}{2.222}$} & \multirow{2}{*}{$\frac{\boldsymbol{P}}{0.136}$} \\
\hline Gender & Male & & & & & \\
\hline & Female & 10 & 10 & 100.0 & & \\
\hline \multirow[t]{2}{*}{ Age(year) } & $>50$ & 14 & 12 & 85.7 & 0.952 & 0.329 \\
\hline & $<=50$ & 6 & 6 & 100.0 & & \\
\hline \multirow[t]{2}{*}{ KPS score } & $>70$ & 9 & 9 & 100.0 & 1.818 & 0.178 \\
\hline & $<=70$ & 11 & 9 & 81.8 & & \\
\hline \multirow[t]{2}{*}{ Tumor size } & $>3 \mathrm{~cm}$ & 15 & 15 & 100.0 & 6.667 & 0.010 \\
\hline & $<=3 \mathrm{~cm}$ & 5 & 3 & 60.0 & & \\
\hline \multirow[t]{3}{*}{ Tumor location } & Frontal lobe & 6 & 4 & 66.7 & 5.185 & 0.745 \\
\hline & Temporal lobe & 11 & 11 & 100.0 & & \\
\hline & Other parts & 3 & 3 & 100.0 & & \\
\hline \multirow[t]{2}{*}{ Tumor excision } & Complete excision & 4 & 2 & 50.0 & 8.889 & 0.003 \\
\hline & Partial excision & 16 & 16 & 100.0 & & \\
\hline
\end{tabular}

Note: Chi-square test was used for analysis.

(Figure 4). With time increasing, the proliferation rates of U87-MG, U251 and LN229 cells in each group were significantly increased $(P<0.05)$. At each time point, there was no significant difference in the proliferation rates between the vector group and the blank group $(P>0.05)$, however, the proliferation rates in the $A Q P 5$ siRNA group was significantly decreased compared with those in the vector and blank groups $(P<0.05)$. The proliferation rates in the Flag $A Q P 5$ group were significantly higher than other groups $(P<0.05)$.

\section{Effect of AQP5 gene silencing on cell cycle distribution of U87-MG, U251 and LN229 cells}

Cell cycle distribution of U87-MG, U251 and LN229 cells was analyzed at $24 \mathrm{~h}$ after transfection. As shown in Supplementary Figure 1, no difference in cell cycle distribution was found between the vector and blank groups. However, in the AQP5 siRNA group, the proportion of cells in the G0-G1 phase were significantly increased while the proportion of cells in $\mathrm{S}$ phase were significantly decreased, and there was no significant difference in percentages of cells in $\mathrm{G} 0$ G1 and S phase between the Flag $A Q P 5$ group with the vector group. As shown in Table 2, AQP5 gene silencing increased the proportion of cells in the G0-G1 phase and decreased the proportion of cells in $\mathrm{S}$ phase (all $P<0.05)$.

\section{Effect of $A Q P 5$ gene silencing on the apoptosis of U87-MG, U251 and LN229 cells}

There was no difference in cell apoptosis rates between the vector and blank groups (both $P>0.05$ ) (Figure 5A, 5B). However, the apoptosis rate of U87-MG, U251 and LN229 increased significantly in the AQP5 siRNA group while decreased significantly in Flag $A Q P 5$ group compared to the vector group $(P<0.05)$. These results indicated that $A Q P 5$ gene silencing increased apoptosis in U87-MG, U251 and LN229 cells.

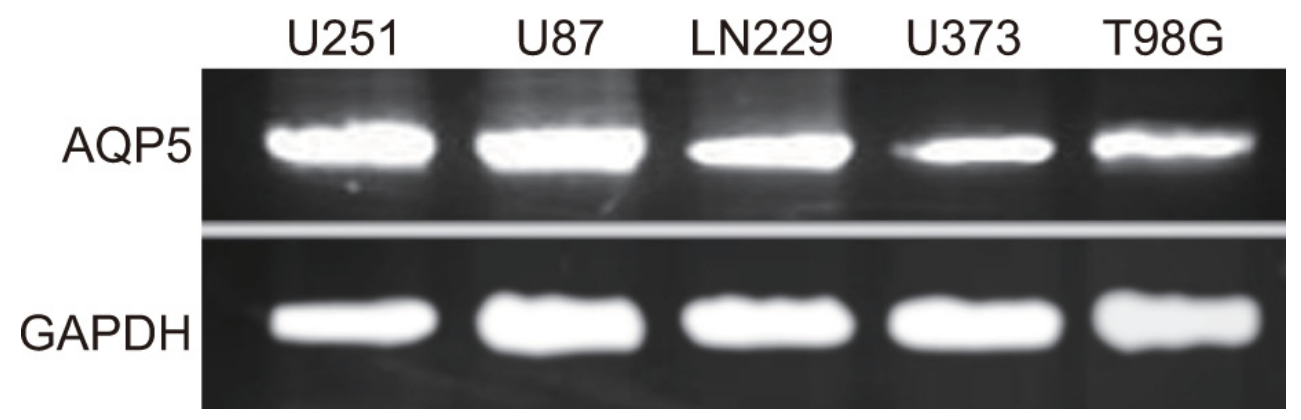

Figure 2: The mRNA expressions in U87-MG, U251, U373, T98G and LN229 cells detected by qRT-PCR. 

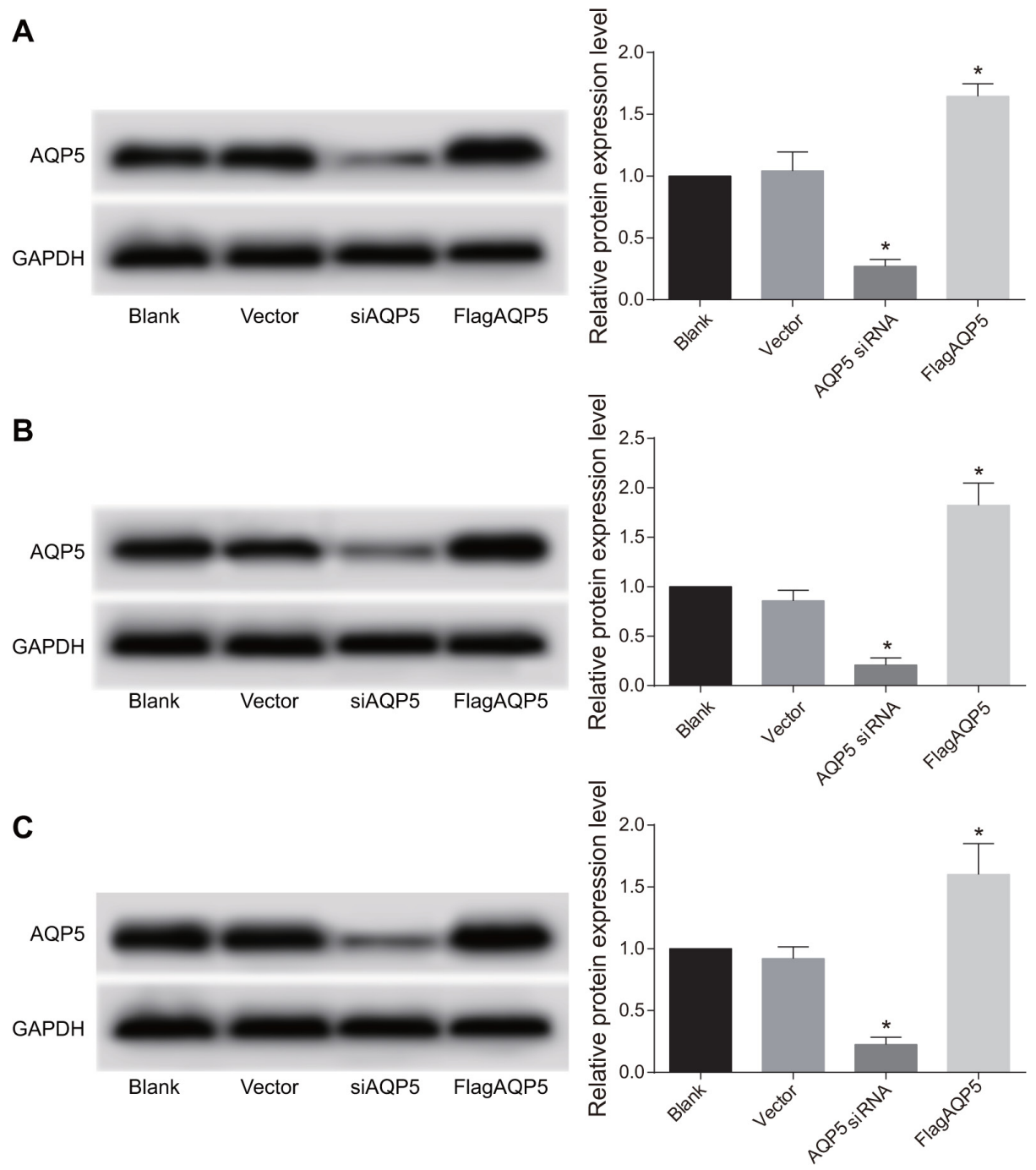

Figure 3: Transfection efficiency of $A Q P 5$ siRNA and Flag $A Q P 5$ in U87-MG, U251 and LN229 cells detected by Western Blotting. (A) the expressions of $A Q P 5$ in U87-MG among four groups; (B) the expressions of $A Q P 5$ in U251 among four groups; (C) the expressions of $A Q P 5$ in LN229 among four groups; one-way analysis of variance (ANOVA) was used for analysis and the experiment was repeated for three times; $* P<0.05$ compared to the vector and blank groups.
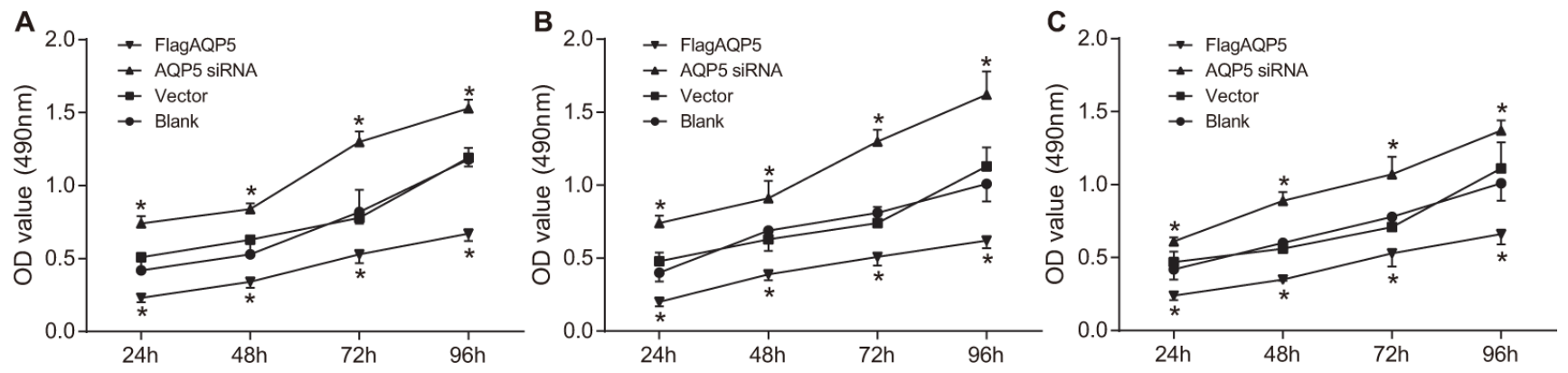

Figure 4: Effect of $A Q P 5$ gene silencing on the proliferation of U87-MG, U251 and LN229 at four time points. (A) the proliferation of U87-MG in four groups at $24 \mathrm{~h}, 48 \mathrm{~h}, 72 \mathrm{~h}$ and $96 \mathrm{~h}$ after transfection; (B) the proliferation of U251 in four groups at $24 \mathrm{~h}$, $48 \mathrm{~h}, 72 \mathrm{~h}$ and $96 \mathrm{~h}$ after transfection; (C) the proliferation of LN229 in four groups at $24 \mathrm{~h}, 48 \mathrm{~h}, 72 \mathrm{~h}$ and $96 \mathrm{~h}$ after transfection; repeated measures analysis of variance was used for comparisons and the experiment was repeated for three times; $* P<0.05$ compared to the vector and blank groups at the same time point. 
Table 2: Cell cycle distribution of U87-MG, U251 and LN229 cells among the blank, vector, $A Q P 5$ siRNA and Flag $A Q P 5$ groups

\begin{tabular}{ccccc}
\hline \multirow{2}{*}{ Cell line } & Group & \multicolumn{3}{c}{ Cell cycle distribution (\%) } \\
\cline { 2 - 4 } & Blank & G0-G1 phase & G2-M phase & S phase \\
\hline U87-MG & $57.74 \pm 6.04$ & $9.67 \pm 1.43$ & $32.59 \pm 7.41$ \\
& Vector & $58.94 \pm 6.36$ & $9.82 \pm 1.21$ & $31.24 \pm 7.51$ \\
& $A Q P 5$ siRNA & $69.34 \pm 3.73^{*}$ & $9.61 \pm 0.95$ & $21.05 \pm 4.62^{*}$ \\
& FlagAQP5 & $56.36 \pm 3.10$ & $9.53 \pm 1.93$ & $34.11 \pm 4.82$ \\
U251 & Blank & $58.96 \pm 2.58$ & $10.20 \pm 0.82$ & $30.82 \pm 2.14$ \\
& Vector & $58.84 \pm 6.11$ & $9.01 \pm 0.34$ & $32.15 \pm 6.12$ \\
& $A Q P 5$ siRNA & $68.33 \pm 4.48^{*}$ & $9.66 \pm 1.25$ & $22.01 \pm 3.43^{*}$ \\
& FlagAQP5 & $57.26 \pm 4.76$ & $10.33 \pm 0.45$ & $32.42 \pm 5.17$ \\
& Blank & $64.47 \pm 2.97$ & $9.50 \pm 3.13$ & $26.03 \pm 3.83$ \\
& Vector & $63.03 \pm 3.92$ & $10.53 \pm 1.97$ & $26.44 \pm 2.36$ \\
& $A Q P 5$ siRNA & $70.70 \pm 4.02^{*}$ & $8.59 \pm 1.56$ & $20.70 \pm 4.37^{*}$ \\
& Flag $A Q P 5$ & $60.85 \pm 3.48$ & $9.68 \pm 1.36$ & $29.48 \pm 2.49$ \\
\hline
\end{tabular}

Note: $* P<0.05$ compared with the vector and blank groups; one-way analysis of variance (ANOVA) was used for analysis and the experiment was repeated for three times.

\section{Effect of $A Q P 5$ gene silencing on the migration of U87-MG, U251 and LN229 cells}

As shown in Figure 6. There was no significant difference in migration ability of U87-MG, U251 and LN229 cells between the vector and blank groups. In the AQP5 siRNA group, the migration abilities were significantly weaker than in the vector and blank groups, while in the Flag $A Q P 5$ group, the abilities were stronger than in the vector and blank groups. The findings showed that $A Q P 5$ gene silencing reduced migration ability of U87-MG, U251 and LN229 cells.
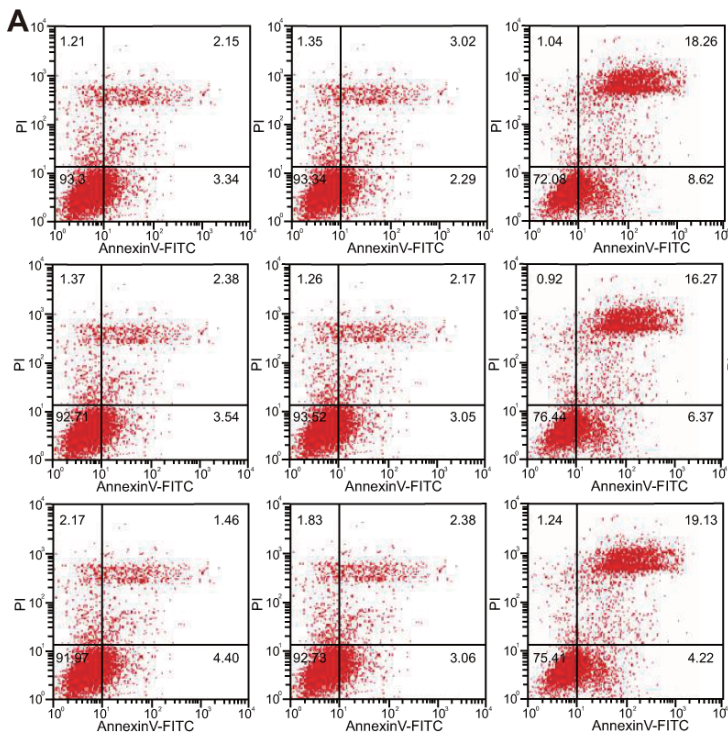

\section{Effect of $A Q P 5$ gene silencing on the activation of EGFR/ERK/p38 MAPK signaling pathway}

As shown in Figure 7, the expressions of EGFR/ ERK/p38 MAPK signaling pathway-related proteins in U87-MG, U251 and LN229 cells showed no significant difference between the vector and blank groups (all $P<0.05)$. Compared with the vector and blank groups, the $A Q P 5$ siRNA group showed significantly decreased expressions of the p-EGFR, p-capase 3, ERK1/2, p-ERK1/2, p38 MAPK and p-p38 MAPK proteins in U87MG, U251 and LN229 cells (all $P<0.05$ ). While there

Figure 5: Effect of AQP5 gene silencing on the cell apoptosis of U87-MG, U251 and LN229. (A) representative dot plots of AnnexinV-FITC /PI in U87-MG, U251 and LN229 cells in each group; (B) the apoptosis rate of U87-MG, U251 and LN229 cells in each group; one-way analysis of variance (ANOVA) was used for analysis and the experiment was repeated for three times; $* P<0.05$ compared to the vector and blank groups. 


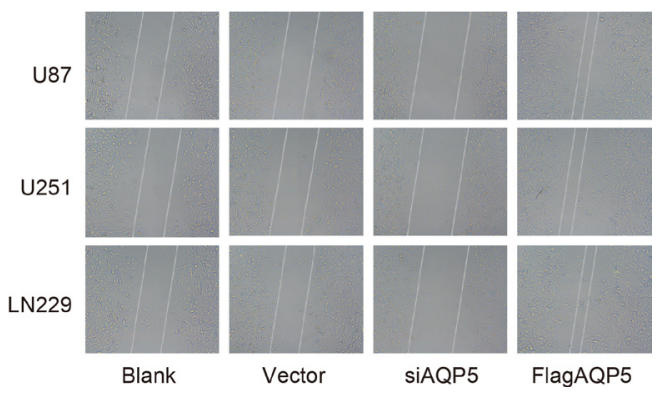

Figure 6: Effect of $A Q P 5$ gene silencing on the cell migration of U87-MG, U251 and LN229.
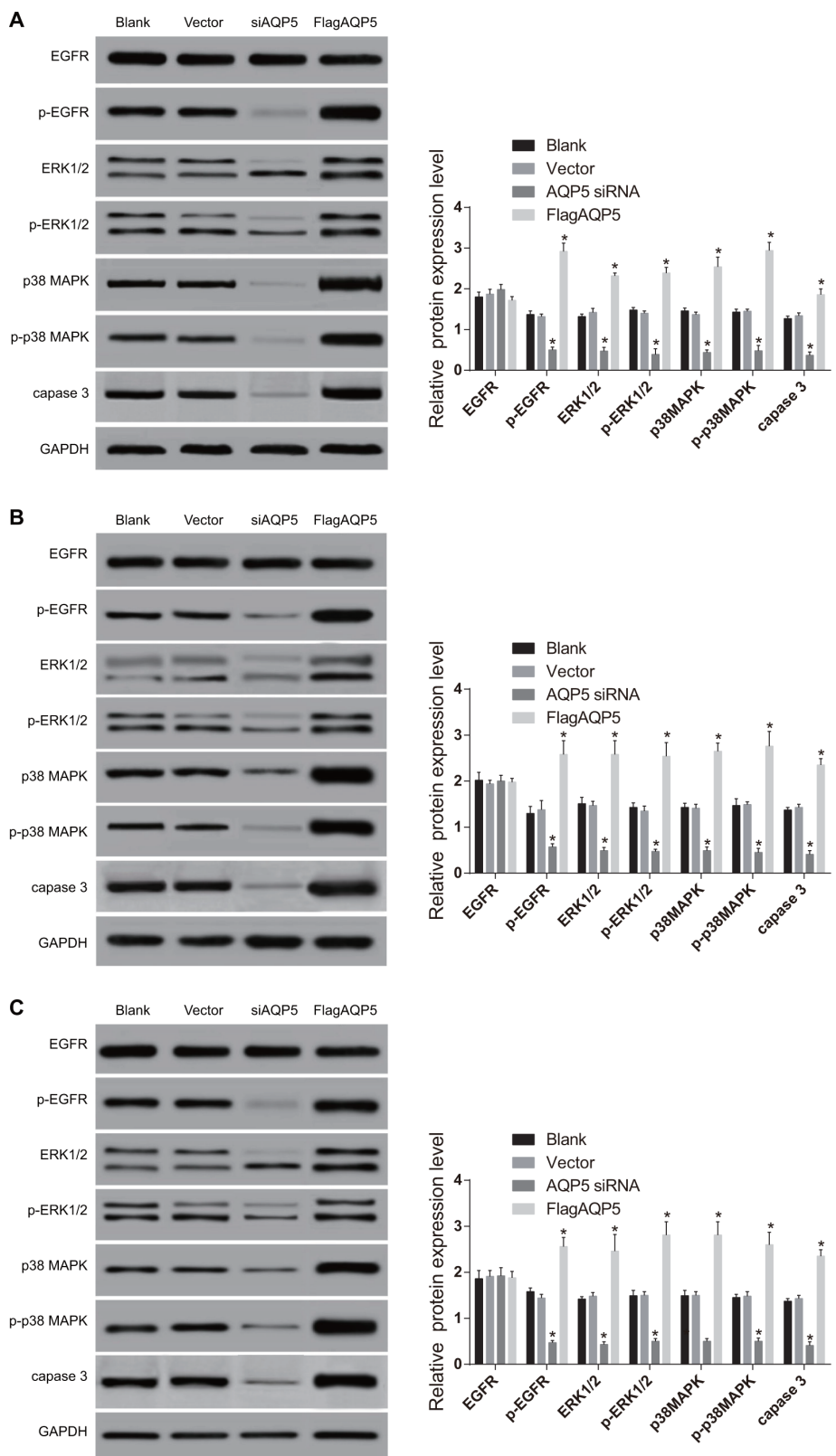

Figure 7: Effect of $A Q P 5$ gene silencing on the expressions of EGFR/ERK/p38 MAPK signaling pathway-related proteins in U251, U87-MG, and LN229 cells detected by Western Blotting. (A) U87-MG; (B) U251; (C) LN229; one-way analysis of variance (ANOVA) was used for analysis and the experiment was repeated for three times; ${ }^{*} P<0.05$ compared to the vector and blank groups. 
was no difference in the protein expressions of EGFR among four groups (all $P>0.05$ ). On the contrary, the expressions of p-EGFR, ERK1/2, p-ERK1/2, p38 MAPK, p-p38 MAPK and capase 3 proteins in U87-MG, U251 and LN229 cells of the FlagAQP5 group were significantly higher than in the vector group and blank group. The results indicated that $A Q P 5$ gene silencing could inhibit the activation of the EGFR/ERK/p38 MAPK signaling pathway.

\section{DISCUSSION}

In this study, we investigated the effects of $A Q P 5$ gene silencing on the proliferation, migration and apoptosis of U87-MG and U251 glioma cells through regulating EGFR/ERK/p38 MAPK signaling pathway. Our findings have demonstrated that AQP5 gene silencing inhibited the proliferation, suppressed migration and promoted the apoptosis of U87-MG, U251 and LN229 glioma cells, indicating that $A Q P 5$ may be a promising target for novel drug development for glioma.

Small interfering RNA (siRNA), an RNAi application, has been widely used for gene silencing, including in glioma [25-27]. Here, we found that siRNAmediated AQP5 gene silencing inhibited the proliferation of U87-MG, U251 and LN229 glioma cells. This inhibition effect likely resulted from AQP5 gene silencing-induced cell cycle arrest in the G0-G1 phase. Meanwhile, the ability of AQP5 in promoting cell proliferation may be dependent on the phosphorylation of a cAMP-protein kinase (PKA) consensus site that is located in a cytoplasmic loop of $A Q P 5$, and phosphorylation of the PKA consensus site is preferentially in tumors [28]. Therefore, blocking phosphorylation of the site might have therapeutic benefits. $A Q P 5$ have been found expressed highly in primary human glioma cells compared with normal tissue, this is in accordance with the study that reported $A Q P S$ (such as $A Q P 1, A Q P 5$ and $A Q P 8$ ) have been observed in highgrade tumors of various tissues [29, 30]. It is confirmed that high expression of $A Q P 5$ was associated with tumor growth, invasion and metastasis in non-small cell lung cancer [31]. Yang et al. found that $A Q P 5$ expression was increased in borderline ovarian tumors and malignant tumors compared to benign and normal ovarian tumors, and that $A Q P 5$ expression was correlated with lymph node metastasis [32]. Together, these results suggest that high AQP5 expression promotes tumor cell proliferation, which agrees with the suppression of tumor cell proliferation observed here after AQP5 gene silencing.

In this study, scratch test showed significantly enhanced migration in Flag $A Q P 5$ cells but downregulation of $A Q P 5$ in cells by $A Q P 5$ gene silencing showed significantly decreased migration. This result provides evidence that there is a potential increased metastatic ability in AQP5 over expressed cells and the effect could be weaken by suppressing $A Q P 5$ gene.
Tumor metastasis involves a series of complex host-tumor interactions and tumor cells interacted with the basal membrane believed to include cell attachment, matrix dissolution, and migration [33, 34]. One mechanism may considered that $A Q P S$ facilitated water permeability in cell protrusions that enhances their formation and accelerate the rate of cell migration $[35,36]$. The study reported by Zhang et al. also showed notably increased water permeability in AQP5 over expressed cells may be enhanced metastases and invasiveness of these cells [37].

Our study also showed that AQP5 gene silencing could increase the apoptosis rate of U87-MG, U251 and LN229 cells. Apoptosis, controlled by gene expression, can help the body adapt to different environmental conditions [38]. The anti-tumor effects of many cancer drugs depend on the induction of apoptosis, and both proapoptotic and anti-apoptotic proteins play important roles in this process [39]. $A Q P$ gene silencing reduces levels of the apoptosis inhibiting proteins c-IAP1, c-IAP2, Livin and X-linked inhibitor of apoptosis protein (XIAP) [40]. Proteins c-IAP1 and c-IAP2 directly inhibit the activity of Caspase-3, Caspase-7 and Caspase-9, thereby inhibiting cell apoptosis [41]. Additionally, XIAP blocks and Livin inhibits could induce cell apoptosis by inhibiting Caspase and activating the TAK1/JNK1 pathways [42, 43]. AQP5 gene silencing might increase apoptosis rates by reducing the levels of these apoptosis-inhibiting proteins.

It was found in the study that AQP5 gene silencing could inhibit the EGFR/ERK/p38 MAPK signaling pathway. This result was consistent with the research by Zhang et al. that in AQP5 highly expressed cells, EGFR phosphorylation was enhanced and the ERK and MAPK signaling pathway was activated, while deletion of AQP5 decreased the activity of the EGFR/ERK/p38 MAPK pathway [44]. The EGFR/ERK/p38 MAPK pathway plays a crucial role in signal transduction in tumors, promoting tumor growth and migration at the transcriptional level $[45,46]$. AQP5 mediates proliferation and migration of tumor cells through the EGFR/ERK/p38 MAPK signaling pathway [47]. MAPK plays a significant role in the differentiation, proliferation and apoptosis of various cells, and ERK as one of three members of MAPK is mainly responsible for proliferative responses $[48,49]$. Glioma cells may overexpress EGFR, which is a tyrosine kinase receptor, resulting in cell proliferation and invasion with downstream effects [50]. VEGF is an important angiogenic factor for glioma, whose expression requires the activation of ERK/MAPK pathway [51]. ERK/MAPK signaling pathway is involved in epithelial-mesenchymal transition (EMT) transformation in SF767 glioma cells, promoting invasive tumor growth [52]. It is reported that $A Q P 1$ plays an important role in water permeability and ultrafiltration, regulating endothelial permeability and angiogenesis [53], which may be further involved in EMT. We then boldly inferred that $A Q P 5$ must function in a similar way as $A Q P 1$ does. Therefore, we supposed that the effects of $A Q P 5$ gene silencing on the 
proliferation, migration and apoptosis of U87-MG, U251 and LN229 cells might be due to its suppression to the activity of EGFR/ERK/p38 MAPK signal pathways.

In summarize, we demonstrated that $A Q P 5$ gene silencing could inhibit the proliferation, reduce the migration and promote the apoptosis of human glioma cells by suppressing EGFR/ERK/p38 MAPK signaling pathway. These findings might be beneficial for the molecular mechanism underlying tumor cell proliferation, migration and apoptosis in human glioma. Nevertheless, further study for the role of AQP5 on glioblastoma stem cells is still required to fully elucidate that if $A Q P 5$ is associated with differentiation of glioma stem cells and whether it could be a potential therapeutic target in glioma.

\section{MATERIALS AND METHODS}

\section{Ethical statement}

This study was approved by the Clinical Experiment Ethical Committee of Renji Hospital, School of Medicine, Shanghai Jiaotong University and all participants signed a document of informed consent.

\section{Sample selection}

From January 2014 to January 2015, twenty patients (age from 25 65 years) from Renji Hospital, School of Medicine, Shanghai Jiaotong University with primary human glioma no more than three months were recruited, including 10 males 10 females. The average age was $(51.63 \pm 11.62)$ years, there were 14 cases of age $>50$ years and 6 cases of age $<=50$ years. The postoperative Karnofsky Performance Scale (KPS) score was 50 100 points with an average score of $(72.70 \pm 8.44)$, there were 11 cases of $>70$ points and 9 cases of $<=70$ points. The diameter of human glioma tissue was $2 \sim 5 \mathrm{~cm}$ with an average value $(3.91 \pm 1.01)$. There were 6 cases of tumor located in frontal lobe, 11 cases in temporal lobe and 3 cases in other parts; 4 cases of complete excision and 16 cases of partial excision. Individuals (age from 28 60) with normal brain tissue were selected as control in the same period, including 10 males and 10 females. The samples of human glioma and normal brain tissue were taken from surgical resection. All subjects underwent radiotherapy and chemotherapy after the surgery.

\section{Immunohistochemistry (IHC)}

Samples were fixed in $10 \%$ formaldehyde, embedded in paraffin and $5 \mu \mathrm{m}$ sections were prepared. Sections were placed at room temperature for $60 \mathrm{~min}$ and then sections were immersed in xylene for dewaxing. Ethanol was used to hydration, afterwards, samples were blocked in 5\% bovine serum albumin (BSA) at room temperature for $20 \mathrm{~min}$. Sections were incubated in AQP5 primary antibody followed by placing at room temperature for $1 \mathrm{~h}$, and then secondary antibody was added. After washing and the visualization with diaminobenzidine (DAB), sections were counterstained with hematoxylin for $2 \mathrm{~min}$ and differentiated by hydrochloric acid alcohol. Then sections were dehydrated, cleared, mounted and microscopy was performed. Images were acquired under the microscope (Olympus Corporation, Japan) and the intensity of the proteins were analyzed by counting the number of positive cells. Randomly selected 10 fields for view $(\times 400)$ and the criteria for results was: negative $(-)$ : no brown staining or positive cells $<10 \%$; positive $(+)$, positive cells $>=10 \%$.

\section{Cell culture and treatment}

Human glioma cell lines U87-MG, U251, U373, T98G and LN229 were purchased from Shanghai Institutes for Biological Sciences, Chinese Academy of Science (Shanghai, China). Cells were cultured in $10 \%$ Dulbecco's modified eagle medium (DMEM, $\mathrm{pH}=7.2$, Gibco Company, Grand Island, NY, USA) containing 10\% fetal bovine serum (FBS) in an incubator at $37^{\circ} \mathrm{C}$ with $5 \%$ $\mathrm{CO}_{2}$. Cell growth and morphology were examined every day and medium was replaced every other day. Serial sub-cultivation was performed when cell density reached $80 \sim 85 \%$ and subsequent experiments were conducted 12 hours after cell adherence. Doubling time of human glioma cells U87-MG, U251, U373, T98G and LN229 were $32.45 \pm 0.52 \mathrm{~h}, 36.45 \pm 0.46 \mathrm{~h}, 32.45 \pm 0.52 \mathrm{~h}$, $36.45 \pm 0.46 \mathrm{~h}$ and $30.96 \pm 0.29 \mathrm{~h}$, respectively. All cell lines were free from mycoplasma contamination (MycoAlert Mycoplasma Detection Kit, Sigma-Aldrich Chemical Company, St Louis MO, USA) in the cultivation.

\section{Quantitative real-time polymerase chain reaction (qRT-PCR)}

Human glioma cells U87-MG, U251, U373, T98G and LN229 were collected in the $1.5 \mathrm{~mL}$ EP tube respectively, each tube with addition of $1 \mathrm{~mL}$ Trizol was followed by placing at room temperature for $10 \mathrm{~min}$. Then $200 \mu \mathrm{L}$ chloroform was added accompanied with shaking tubes violently for $10 \mathrm{~s}$. After placing at room temperature for $5 \mathrm{~min}$, cells were centrifuged at $12,000 \mathrm{~g}$ at $4{ }^{\circ} \mathrm{C}$ for $5 \mathrm{~min}$, the supernatant was transferred to another tube subsequently for the next step. Then $200 \mu \mathrm{L}$ isopropanol was added, and cells were placed at $4^{\circ} \mathrm{C}$ for $10 \mathrm{~min}$ and centrifuged at $12,000 \mathrm{~g}$ at $4^{\circ} \mathrm{C}$ for $10 \mathrm{~min}$. The pellets were washed by $1 \mathrm{~mL} \mathrm{75 \%}$ ethanol and followed by centrifugation at $12,000 \mathrm{~g}$ at $4^{\circ} \mathrm{C}$ for $10 \mathrm{~min}$. At last, the pellets were dissolved in diethylpyrocarbonate (DEPC) -treated water for $15 \mathrm{~min}$. The concentration of RNA was calculated by the absorbance of RNA. Complementary DNA (cDNA) was synthesized from RNA samples (2 $\mu \mathrm{g}$ each sample). The reverse transcriptase reaction 
was performed: $3 \mu \mathrm{L}$ of anchored oligo (dT) primers was added, DEPC-treated water was used to adjust total volume at $13 \mu \mathrm{L}$. Then heated at $5 \mathrm{~min}$ for $70^{\circ} \mathrm{C}$ (denaturation). After quick chilling on ice, the following were added (total $30 \mu \mathrm{L}$ ): $6 \mu \mathrm{L} 5 \times$ M-MLV buffer, $2 \mu \mathrm{L}$ deoxyribonucleoside triphosphate (dNTP), $0.5 \mu \mathrm{L}$ RNase inhibitor, $1.5 \mu \mathrm{L}$ Moloney murine leukemia virusreverse transcriptase (MMLV-RT) and DEPC-treated water. The condition of reverse transcription was: $42^{\circ} \mathrm{C}$ for $60 \mathrm{~min}, 95^{\circ} \mathrm{C}$ for $10 \mathrm{~min},-40^{\circ} \mathrm{C}$ after termination. qRT-PCR was conducted using the PCR kit (A3500, Promega Corp., Madison, Wisconsin, USA) and the total volume of PCR reaction included $20 \mu \mathrm{L}: 1 \mu \mathrm{L}$ cDNA, $1 \mu \mathrm{L}$ upstream primer, $1 \mu \mathrm{L}$ downstream primer, $10 \mu \mathrm{L}$ mixture and $8 \mu \mathrm{L}$ DEPC-treated water. Forty cycles were performed under the conditions: pre-denaturation at $95^{\circ} \mathrm{C}$ for $10 \mathrm{~min}$; denaturation at $94^{\circ} \mathrm{C}$ for $30 \mathrm{~s}$, annealing at $72^{\circ} \mathrm{C}$ for $1 \mathrm{~min}$, and extension at $72^{\circ} \mathrm{C}$ for $5 \mathrm{~min}$. Then reextension at $72^{\circ} \mathrm{C}$ for $5 \mathrm{~min}$. The real-time PCR products were analyzed by $70 \mathrm{~V}$ agarose gel electrophoresis for $25 \mathrm{~min}$ and pictured under the UV light. GAPDH was amplified as the internal control and primer sequences were: upstream: 5' -ATCACTGCCACCCAGAAGAC-3', downstream: 5'- AGATCCACGACGGACACATT-3'. AQP5 primer sequences were: upstream: 5' -CTATGAG TCCGAGGAGGATT-3', downstream: 5'- GCTTCGCTG TCATCTGTT-3' [24].

\section{$A Q P 5$ siRNA design and vector construction}

$A Q P 5$ specific small interfering RNA (AQP5 siRNA) sequences were 5'-CGGUGGUCAUGAAUCGG UUTT-3' for the sense strand and 5'-AACCGAUUCAUGA CCACCGCA-3' for the anti-sense strand. The sense strand sequences for negative control siRNA were 5'-UUCU CCGAACGUGUCACGUTT-3' and the anti-sense strand were 5'-ACGUGACACGUUCGGAGAATT-3'.

\section{Cell transfection}

Human glioma cells U87-MG, U251 and LN229 were assigned into four groups respectively: the blank group (no transfection), the vector group (transfected with empty plasmid), the Flag $A Q P 5$ group (transfected with overexpression plasmid) and the $A Q P 5$ siRNA group (transfected with AQP5 siRNA plasmid). Cells were seeded in a 6-well plate at a density of $10^{5}$ cell/well and each well containing $2 \mathrm{~mL}$ of DMEM with $10 \%$ FBS. Cells were then cultured for $12 \mathrm{~h}$, and transfection was performed when cells reached density of $80 \%$. Cells were subjected to starvation in $800 \mu \mathrm{L} /$ well serum- and antibody-free DMEM medium before transfection. Mixed medium of different experimental plasmid and transfection reagent was prepared. Six sterile $1.5 \mathrm{~mL}$ EP tubes were selected: For tubes 1, 3 and 5: 800 ng of overexpression plasmid Flag $A Q P 5, A Q P 5$ siRNA plasmid and empty plasmid were added to $50 \mu \mathrm{L}$ of serum- and antibody-free DMEM medium. For tubes 2, 4 and 6: $2.5 \mu \mathrm{L}$ of GeneJet ${ }^{\mathrm{TM}}$ II DNA extracorporeal transfection reagent (SIGNAGEN LABORATORIES LLC., Madrid, Spain) was added to $50 \mu \mathrm{L}$ of serum- and antibody-free DMEM medium. Tubes 1 and 2, tubes 3 and 4 as well as tubes 5 and 6 were mixed respectively, and preserved at room temperature for $20 \mathrm{~min}$. Then the mixed medium was transferred into the 6 -well plate at $100 \mu \mathrm{L}$ per well followed by $6 \mathrm{~h}$ of incubation at $37^{\circ} \mathrm{C}$ with $5 \% \mathrm{CO}_{2}$, and another $24 \mathrm{~h}$ of incubation was performed with addition of $100 \mu \mathrm{L}$ of complete culture medium to each well. After that, cells were collected for further use.

\section{3-(4, 5-Dimethylthiazol-2-yl)-2, 5-diphenyltetrazolium bromide (MTT) assay}

U87-MG, U251 and LN229 cell lines in the logarithmic phase were independently assigned into the blank, vector, Flag $A Q P 5$ and $A Q P 5$ siRNA groups, and after trypsin digestion, cell suspension was prepared. Cells in each group were seeded in a 96-well plate at $10^{3}$ cell/well. Four duplicate wells were seeded for each group. Four hour prior to cell collection, $10 \mu \mathrm{L}$ of MTT solution $(5 \mu \mathrm{g} / \mu \mathrm{L})$ was added to each well. Medium was then removed and replaced with $100 \mu \mathrm{L}$ of dimethyl sulfoxide (DMSO) in each well followed by incubation for $10 \mathrm{~min}$ protected from light. An ultraviolet spectrophotometer (Thermo Fisher Scientific Inc., USA) was used to detect absorbance of each well at the $490 \mathrm{~nm}$ wavelength.

\section{Flow cytometry with AnnexinV-FITC/PI staining}

AnnexinV-FITC/PI methods were used to separate early apoptotic cells from late apoptotic cells. U87-MG, U251 and LN229 cell lines in the logarithmic phase were independently assigned into the blank, vector, Flag $A Q P 5$ and $A Q P 5$ siRNA groups. Cells were treated with cisplatin (CDDP, $4 \mu \mathrm{M} / \mathrm{L}$ ) $24 \mathrm{~h}$ before transfection. An AnnexinVFITC/PI kit (Becton, Dickinson and Company, New Jersey, USA) was used to stain cells for 15 min protected from light after transfection for $24 \mathrm{~h}$. Flow cytometry and fluorescence activated cell sorting (FACS) (Becton, Dickinson and Company, New Jersey, USA) were applied to detect cell apoptosis immediately after incubation. The experiment was repeated for three times in each group.

\section{Flow cytometry with PI staining}

U87-MG, U251 and LN229 cell lines in the logarithmic phase were independently assigned into the blank, vector, Flag $A Q P 5$ and $A Q P 5$ siRNA groups. Cells were seeded in a 6-well plate for $24 \mathrm{~h}$ of transfection. Digestion was performed using $0.25 \%$ trypsin, and the supernatant was discarded after $5 \mathrm{~min}$ of centrifugation at $3000 \mathrm{~g}$ at $4^{\circ} \mathrm{C}$. Cells were washed three times with 
phosphate buffer (PBS), and pre-cooled $75 \%$ ethanol was then applied to fix cells overnight. Ethanol was discarded after $5 \mathrm{~min}$ of centrifugation at $3000 \mathrm{~g}$ at $4^{\circ} \mathrm{C}$, and cell concentration was adjusted to $10^{5}$ cell $/ \mathrm{mL}$. Cell suspension $(1 \mathrm{~mL})$ was extracted for PI staining with a $20 \mathrm{~min}$ of incubation protected from light at $37^{\circ} \mathrm{C}$. Flow cytometry and ModFit Software (Verity Software House Inc., Topsham, ME, USA) were used to detect cell cycle and to calculate percentages of the total cells in each stage. The experiment was repeated for three times in each group.

\section{Scratch test}

U87-MG, U251 and LN229 cell lines in the logarithmic phase were independently assigned into the blank, vector, Flag $A Q P 5$ and $A Q P 5$ siRNA groups. Cells were plated into a 6 -well plate at a density of $5 \times 10^{5}$ cell $/ \mathrm{mL}$. When the density reached to $90 \%$, cells were cultured in serum-free medium and starved for $24 \mathrm{~h}$, and when the density reached to $100 \%$, using a sterile $200 \mu \mathrm{L}$ pipette tips to draw a line softly and quickly in monolayer cultures of cells. Then suspended cells were washed away by PBS, and cells were cultured in serum-free medium continually. After incubation for $24 \mathrm{~h}$, migration of the cells was photographed.

\section{Western blotting}

Supernatant was discarded and U87-MG, U251 and LN229 cells were collected and independently assigned into the blank, vector, FlagAQP5 and AQP5 siRNA groups, followed by washing three times with PBS. Cells were gently scraped and transferred to $1.5 \mathrm{~mL}$ EP tubes, and the supernatant was discarded after $5 \mathrm{~min}$ of centrifugation at $3000 \mathrm{~g}$ at $4^{\circ} \mathrm{C}$. Cells were lysed in radioimmunoprecipitation assay (RIPA) buffer on ice for $40 \mathrm{~min}$, followed by $10 \mathrm{~min}$ of centrifugation at $12000 \mathrm{~g}$ at $4^{\circ} \mathrm{C}$. The supernatant was extracted and a bicinchoninic acid (BCA) kit (Beyotime Biotechnology Co., Shanghai, China) was used to determine the protein concentration of U87-MG, U251 and LN229 cells. Total protein $(50 \mu \mathrm{g})$ of U87-MG, U251 and LN229 cells was used for SDSPAGE at $70 \mathrm{~V}$ for $120 \mathrm{~min}$, followed by transfer to a polyvinylidene fluoride (PVDF) membrane and incubation with $5 \%$ skim milk at room temperature for $1.5 \mathrm{~h}$. The membrane was then incubated with rabbit antibodies (AQP5 antibody 1:1000, p-EGFR antibody 1:500, EGFR antibody 1:1000, p-ERK1/2 antibody 1:1000, ERK1/2 antibody 1:1000, p-p38 MAPK antibody 1:500, p38 MAPK antibody 1:500, and GAPDH antibody 1:2000) for $2 \mathrm{~h}$, followed by reservation overnight at $4{ }^{\circ} \mathrm{C}$. All the antibodies were purchased from Abcam Inc., Cambridge, MA, USA. Then the membrane was washed three times with tris-buffered saline tween (TBST) ( $\mathrm{pH} 7.4)$, and goat anti-rabbit $\operatorname{IgG}$ labeled with horseradish peroxidase (1:2000) was added, followed by incubation at room temperature for $1 \mathrm{~h}$. Photos were scanned after development with chemiluminescence reagent ECL (Vazyme Biotech Co., Ltd, Jiangsu, China), and Image J software was used to analyze relative protein expression based on gray levels.

\section{Statistical analysis}

SPSS 21.0 software (SPSS Inc., Chicago, IL, USA) was used for statistical analysis. The measurement data were presented as mean \pm standard deviation, $t$ test was used for comparison between two groups, comparison of multiple groups was conducted with One-way analysis of variance (ANOVA) and pairwise comparison among groups was done with Student-Newman-Keuls (SNK) method. Repeated measures analysis of variance was used for comparisons of cell proliferation at different time points, and Wilcoxon's signed-rank test was performed for non-normally distributed data. The enumeration data were expressed as ratio or percentage and analyzed by chi-square test. $P<0.05$ was considered statistically significant.

\section{ACKNOWLEDGMENTS AND FUNDING}

This work was supported by grants from the National Nature Science Foundation (81372705), the Shanghai Science and Technology Development Fund (10JC1409802) and the Wu Jieping Medical Foundation (320675011092).We would like to thank the reviewers for their helpful comments on this paper.

\section{CONFLICTS OF INTEREST}

None

\section{REFERENCES}

1. Amirian ES, Armstrong GN, Zhou R, Lau CC, Claus EB, Barnholtz-Sloan JS, Il'yasova D, Schildkraut J, Ali-Osman F, Sadetzki S, Johansen C, Houlston RS, Jenkins RB, et al. The Glioma International Case-Control Study: A Report From the Genetic Epidemiology of Glioma International Consortium. Am J Epidemiol. 2016; 183:85-91.

2. Brat DJ, Parisi JE, Kleinschmidt-DeMasters BK, Yachnis AT, Montine TJ, Boyer PJ, Powell SZ, Prayson RA, McLendon RE, Neuropathology Committee CoAP. Surgical neuropathology update: A review of changes introduced by the who classification of tumours of the central nervous system, 4th edition. Arch Pathol Lab Med. 2008; 132:993-1007.

3. Philip-Ephraim EE, Eyong KI, Williams UE, Ephraim RP. The role of radiotherapy and chemotherapy in the treatment of primary adult high grade gliomas: Assessment of patients for these treatment approaches and the common immediate side effects. ISRN Oncol. 2012; 2012:902178.

4. Frenel JS, Botti M, Loussouarn D, Campone M. [prognostic and predictive factors for gliomas in adults]. Bull Cancer. 2009; 96:357-367. 
5. Alvarez de Eulate-Beramendi S, Alvarez-Vega MA, Balbin M, Sanchez-Pitiot A, Vallina-Alvarez A, Martino-Gonzalez J. Prognostic factors and survival study in high-grade glioma in the elderly. Br J Neurosurg. 2016; 30:330-6.

6. Maresch J, Birner P, Zakharinov M, Toumangelova-Uzeir K, Natchev S, Guentchev M. Additive effect on survival of raf kinase inhibitor protein and signal transducer and activator of transcription 3 in high-grade glioma. Cancer. 2011; 117:2499-2504.

7. Hamard L, Ratel D, Selek L, Berger F, van der Sanden B, Wion $\mathrm{D}$. The brain tissue response to surgical injury and its possible contribution to glioma recurrence. J Neurooncol. 2016; 128:1-8.

8. Sareddy GR, Li X, Liu J, Viswanadhapalli S, Garcia L, Gruslova A, Cavazos D, Garcia M, Strom AM, Gustafsson JA, Tekmal RR, Brenner A, Vadlamudi RK. Selective Estrogen Receptor beta Agonist LY500307 as a Novel Therapeutic Agent for Glioma. Sci Rep. 2016; 6:24185.

9. Shaw EG, Wang M, Coons SW, Brachman DG, Buckner JC, Stelzer KJ, Barger GR, Brown PD, Gilbert MR, Mehta MP. Randomized trial of radiation therapy plus procarbazine, lomustine, and vincristine chemotherapy for supratentorial adult low-grade glioma: initial results of RTOG 9802. J Clin Oncol. 2012; 30:3065-70.

10. Huse JT, Holland EC. Targeting brain cancer: Advances in the molecular pathology of malignant glioma and medulloblastoma. Nat Rev Cancer. 2010; 10:319-331.

11. Ohgaki H, Kleihues P. Genetic pathways to primary and secondary glioma. Am J Pathol. 2007; 170:1445-1453.

12. Karabasil MR, Hasegawa T, Azlina A, Purwanti N, Purevjav J, Yao C, Akamatsu T, Hosoi K. Trafficking of gfpAQP5 chimeric proteins conferred with unphosphorylated amino acids at their pka-target motif ((152)srrts) in mdck-ii cells. J Med Invest. 2009; 56:55-63.

13. Verkman AS, Anderson MO, Papadopoulos MC. Aquaporins: Important but elusive drug targets. Nat Rev Drug Discov. 2014; 13:259-277.

14. Ning Y, Ying B, Han S, Wang B, Wang X, Wen F. Polymorphisms of aquaporin5 gene in chronic obstructive pulmonary disease in a chinese population. Swiss Med Wkly. 2008; 138:573-578.

15. Jung HJ, Park JY, Jeon HS, Kwon TH. Aquaporin-5: a marker protein for proliferation and migration of human breast cancer cells. PLoS One. 2011; 6:e28492.

16. Kang SK, Chae YK, Woo J, Kim MS, Park JC, Lee J, Soria JC, Jang SJ, Sidransky D, Moon C. Role of human aquaporin 5 in colorectal carcinogenesis. Am J Pathol. 2008; 173:518-25.

17. Burghardt B, Elkaer ML, Kwon TH, Racz GZ, Varga G, Steward MC, Nielsen S. Distribution of aquaporin water channels AQP1 and AQP5 in the ductal system of the human pancreas. Gut. 2003; 52:1008-16.

18. Xin LB, Jiang XX, Ye XL, Wu RJ, Xu KH, Ma JY, Lin J. [AQP5 gene silencing inhibits proliferation and migration of ectopic endometrial glandular epithelial cells in endometriosis]. Zhejiang Da Xue Xue Bao Yi Xue Ban. 2015; 44:285-92.

19. Deb P, Pal S, Dutta V, Boruah D, Chandran VM, Bhatoe HS. Correlation of expression pattern of aquaporin-1 in primary central nervous system tumors with tumor type, grade, proliferation, microvessel density, contrast-enhancement and perilesional edema. J Cancer Res Ther. 2012; 8:571-577.

20. Qiu B, Li X, Sun X, Wang Y, Jing Z, Zhang X, Wang Y. Overexpression of aquaporin1 aggravates hippocampal damage in mouse traumatic brain injury models. Mol Med Rep. 2014; 9:916-922.

21. Diaz-Cano SJ. Re: Pomerance et al. High-level expression, activation, and subcellular localization of p38-map kinase in thyroid neoplasms. J pathol 2006; 209:298-306. J Pathol. 2006; 210:133-134.

22. Rogers SJ, Box C, Chambers P, Barbachano Y, Nutting CM, Rhys-Evans P, Workman P, Harrington KJ, Eccles SA. Determinants of response to epidermal growth factor receptor tyrosine kinase inhibition in squamous cell carcinoma of the head and neck. J Pathol. 2009; 218:122-130.

23. Angulo B, Suarez-Gauthier A, Lopez-Rios F, Medina PP, Conde E, Tang M, Soler G, Lopez-Encuentra A, Cigudosa JC, Sanchez-Cespedes M. Expression signatures in lung cancer reveal a profile for egfr-mutant tumours and identify selective pik3ca overexpression by gene amplification. J Pathol. 2008; 214:347-356.

24. Skowronska A, Mlotkowska P, Majewski M, Nielsen S, Skowronski MT. Expression of aquaporin 1 and 5 and their regulation by ovarian hormones, arachidonic acid, forskolin and cAMP during implantation in pigs. Physiol Res. 2016; 65:637-50.

25. Nishimura $Y$, Mieda $H$, Ishii J, Ogino C, Fujiwara $T$, Kondo A. Targeting cancer cell-specific rna interference by sirna delivery using a complex carrier of affibody-displaying bio-nanocapsules and liposomes. J Nanobiotechnology. 2013; 1119.

26. Trougakos IP, So A, Jansen B, Gleave ME, Gonos ES. Silencing expression of the clusterin/apolipoprotein $\mathrm{j}$ gene in human cancer cells using small interfering RNA induces spontaneous apoptosis, reduced growth ability, and cell sensitization to genotoxic and oxidative stress. Cancer Res. 2004; 64:1834-42.

27. Zhou Y, Su Z, Huang Y, Sun T, Chen S, Wu T, Chen G, Xie X, Li B, Du Z. The Zfx gene is expressed in human gliomas and is important in the proliferation and apoptosis of the human malignant glioma cell line U251. J Exp Clin Cancer Res. 2011; 30:114.

28. Woo J, Lee J, Chae YK, Kim MS, Baek JH, Park JC, Park MJ, Smith IM, Trink B, Ratovitski E, Lee T, Park B, Jang SJ, et al. Overexpression of AQP5, a putative oncogene, promotes cell growth and transformation. Cancer Lett. 2008; 264:54-62.

29. Andersen P, Villingshoj M, Poulsen HS, Stockhausen MT. Improved response by co-targeting EGFR/EGFRvIII and 
Src family kinases in human cancer cells. Cancer Invest. 2009; 27:178-83.

30. Hoque MO, Soria JC, Woo J, Lee T, Lee J, Jang SJ, Upadhyay S, Trink B, Monitto C, Desmaze C, Mao L, Sidransky D, Moon C. Aquaporin 1 is overexpressed in lung cancer and stimulates NIH-3T3 cell proliferation and anchorage-independent growth. Am J Pathol. 2006; 168:1345-53.

31. Song T, Yang H, Ho JC, Tang SC, Sze SC, Lao L, Wang Y, Zhang KY. Expression of aquaporin 5 in primary carcinoma and lymph node metastatic carcinoma of non-small cell lung cancer. Oncol Lett. 2015; 9:2799-804.

32. Yang JH, Shi YF, Cheng Q, Deng L. Expression and localization of aquaporin-5 in the epithelial ovarian tumors. Gynecol Oncol. 2006; 100:294-9.

33. Gallagher PG, Bao Y, Prorock A, Zigrino P, Nischt R, Politi V, Mauch C, Dragulev B, Fox JW. Gene expression profiling reveals cross-talk between melanoma and fibroblasts: implications for host-tumor interactions in metastasis. Cancer Res. 2005; 65:4134-46.

34. Liotta LA, Steeg PS, Stetler-Stevenson WG. Cancer metastasis and angiogenesis: an imbalance of positive and negative regulation. Cell. 1991; 64:327-36.

35. Hu J, Verkman AS. Increased migration and metastatic potential of tumor cells expressing aquaporin water channels. FASEB J. 2006; 20:1892-4.

36. Verkman AS. More than just water channels: unexpected cellular roles of aquaporins. J Cell Sci. 2005; 118:3225-32.

37. Zhang Z, Chen Z, Song Y, Zhang P, Hu J, Bai C. Expression of aquaporin 5 increases proliferation and metastasis potential of lung cancer. J Pathol. 2010; 221:210-20.

38. Xiang J, Guo S, Jiang S, Xu Y, Li J, Li L, Xiang J. Silencing of Long Non-Coding RNA MALAT1 Promotes Apoptosis of Glioma Cells. J Korean Med Sci. 2016; 31:688-94.

39. Pandya V, Glubrecht D, Vos L, Hanson J, Damaraju S, Mackey J, Hugh J, Goping IS. The pro-apoptotic paradox: the $\mathrm{BH} 3$-only protein $\mathrm{Bcl}-2$ interacting killer (Bik) is prognostic for unfavorable outcomes in breast cancer. Oncotarget. 2016; 7:33272-85. doi: 10.18632/ oncotarget.8924.

40. Gao L, Gao Y, Li X, Howell P, Kumar R, Su X, Vlassov AV, Piazza GA, Riker AI, Sun D, Xi Y. Aquaporins mediate the chemoresistance of human melanoma cells to arsenite. Mol Oncol. 2012; 6:81-7.

41. He W, Wang Q, Srinivasan B, Xu J, Padilla MT, Li Z, Wang X, Liu Y, Gou X, Shen HM, Xing C, Lin Y. A JNK-mediated autophagy pathway that triggers c-IAP degradation and necroptosis for anticancer chemotherapy. Oncogene. 2014; 33:3004-13.
42. Zhang D, Zhao N, Ma B, Wang Y, Zhang G, Yan X, $\mathrm{Hu}$ S, T Xu. Procaspase-9 induces its cleavage by transnitrosylating XIAP via the Thioredoxin system during cerebral ischemia-reperfusion in rats. Sci Rep. 2016; $6: 24203$.

43. Chung CY, Park YL, Kim N, Park HC, Park HB, Myung DS, Kim JS, Cho SB, Lee WS, Joo YE. Expression and prognostic significance of Livin in gastric cancer. Oncol Rep. 2013; 30:2520-8.

44. Zhang Z, Chen Z, Song Y, Zhang P, Hu J, Bai C. Expression of aquaporin 5 increases proliferation and metastasis potential of lung cancer. J Pathol. 2010; 221:210-220.

45. Singh B, Schneider M, Knyazev P, Ullrich A. UV-induced EGFR signal transactivation is dependent on proligand shedding by activated metalloproteases in skin cancer cell lines. Int J Cancer. 2009; 124:531-9.

46. Thomson S, Petti F, Sujka-Kwok I, Epstein D, Haley JD. Kinase switching in mesenchymal-like non-small cell lung cancer lines contributes to EGFR inhibitor resistance through pathway redundancy. Clin Exp Metastasis. 2008; 25:843-54.

47. $\mathrm{Xu} \mathrm{JL}, \mathrm{Xia} \mathrm{R}$. The emerging role of aquaporin 5 (AQP5) expression in systemic malignancies. Tumour Biol. 2014; 35:6191-2.

48. Wen YY, Yang ZQ, Song M, Li BL, Zhu JJ, Wang EH. Siah1 induced apoptosis by activation of the jnk pathway and inhibited invasion by inactivation of the erk pathway in breast cancer cells. Cancer Sci. 2010; 101:73-79.

49. Du MR, Zhou WH, Yan FT, Zhu XY, He YY, Yang JY, Li DJ. Cyclosporine a induces titin expression via mapk/erk signalling and improves proliferative and invasive potential of human trophoblast cells. Hum Reprod. 2007; 22:2528-2537.

50. Butowski NA, Chang SM. Glial tumors: The current state of scientific knowledge. Clin Neurosurg. 2006; 53 106-113.

51. Guo G, Yao W, Zhang Q, Bo Y. Oleanolic acid suppresses migration and invasion of malignant glioma cells by inactivating mapk/erk signaling pathway. PLoS One. 2013; 8:e72079.

52. Liu L, Dai Q, Min Z, Zhang M. [Transforming growth factor beta1 enhances the invasiveness of human glioma cell line via ERK/MAPK pathway]. Nan Fang Yi Ke Da Xue Xue Bao. 2013; 33:1744-7.

53. Kim YL. Update on mechanisms of ultrafiltration failure. Perit Dial Int. 2009; 29:123-127. 